[3] Haglund, E., et al., Differences in physical activity patterns in patients with spondylarthritis. Arthritis Care Res (Hoboken), 2012. 64(12): p. 1886-94.

Disclosure of Interests: None declared

DOI: 10.1136/annrheumdis-2019-eular.1414

\section{AB1357-HPR PROSPECTIVE ANALYSIS OF IRREVERSIBLE ORGAN DAMAGE IN PATIENTS OF KYRGYZ NATIONALITY}

Gulazyk Koilubaeva ${ }^{1}$, Elmira Karimova ${ }^{1}$, Altynai Moldobaeva ${ }^{1}$,

Aijamal Jumakadyrova ${ }^{1}$, on behalf of G. Koilubaeva, E. Karimova, A. Moldobaeva, A. Jumakadyrova. ${ }^{1}$ Togolok Moldo Street, 3, Bishkek, Kyrgyzstan

Background Special attention in recent decades has been paid to the accumulation of irreversible organ effects (SLICC) with systemic lupus erythematosus (SLE) in the form of most diseases, as well as therapy. Along with an increase in survival, the structure of lethal outcomes also changed: cardiovascular pathology, complications of drug therapy, malignant neoplasms, chronic renal and pulmonary insufficiency.

Objectives Study of irreversible organ damage in patients with SLE, prospective observation.

Methods The study included $150(26.31 \%)$ Kyrgyz patients out of 570 with a reliable diagnosis of SLE, female (96\%), young age (median - 34 [26; 44]), Kyrgyz nationality $(89.33 \%)$, high - $61(40.66 \%)$ and very high activity - $40(26.67 \%)$, with the duration of SLE at 1 observation point from 7 months to 10 years, with dynamic observation from 1 year to 3 years. The development of irreversible organ damage was assessed on a scale of damage index (PI) developed by the International Cooperation Organization of SLE Clinics. The absence of damage was rated as 0 points, low $\mathrm{PI}$ - 1 point, average PI from 2 to 4 points, high PI more than 4 points. Results In the Kyrgyz cohort at the initial visit, the absence of irreversible organ damage was observed in the overwhelming majority of patients - in 127 (84.67\%) of 150 . In 1 observation point with organ lesions there were 23 patients (15.33\%) out of 150 , of which with low PI values - 14 (60.87\%), with average values - 9 (39.13\%), there were no patients with high $\mathrm{PI}$ values, due to the small duration of the disease (median - $3[0.7 ; 10]$ of the year). During the initial visit, irreversible organ damage was observed due to the administration of $\mathrm{HA}(8)$ : aseptic necrosis of the femoral heads - in 2, spondylopathy - in 3, cataract - in 2 and diabetes - in 1. Second point of observation was damage to the respiratory organs - 7 patients: pulmonary fibrosis - in 3 and pulmonary arterial hypertension - in 4 . The next in frequency were CNS lesions - in 6 patients: ischemic stroke - in 4 and cognitive impairment - in 2. By the final observation point, organ damage was observed already in $43(28.67 \%)$ patients out of 150 without statically significant progression ( $p>0.05$ ), which in half of the cases were due to the administration of GC - in 24 $(55.82 \%)$ as aseptic necrosis of the femoral heads - in 5, spondylopathy - in 7, cataracts - in 9 and diabetes - in 3. In second place were injuries of the respiratory organs - in 9 (20.93\%) of 43: pulmonary fibrosis - in 5 and pulmonary arterial hypertension (PAH) - in 4. Next in frequency were CNS injuries - in 6 (13.95\%) of 43: ischemic stroke at 4 and cognitive impairments - in the kidneys were observed 2. Damage - $4(9.30 \%)$ of 43 patients: with a reduction in glomerular filtration rate (GFR) in the terminal 3 and the development of CRF 1 as starting severe lupus glomerulonephritis.

Conclusion Under dynamic observation, irreversible organ damage was detected in $28.67 \%$ of cases, which was $13.34 \%$ more compared to the initial state, without statically significant progression ( $p>0.05$ ), mainly due to the administration of $\mathrm{GC}(55,82 \%)$.

Acknowledgement I would like to express my deep gratitude to Professor E. Nosonov and Professor S. Soloviev, my research assistances, for their patient guidance, enthusiastic encouragement and useful critiques of this research work. Disclosure of Interests None declared

DOI: 10.1136/annrheumdis-2019-eular.3900

\section{AB1358-HPR SUICIDAL BEHAVIORS IN PATIENTS WITH INTRAVENOUS BIOLOGIC THERAPIES}

Amparo Lopez Esteban ${ }^{1}$, Roberto Daniel Gonzalez Benitez ${ }^{1}$, Aurora Alonso Amigo ${ }^{2}$, Aurora Alonso Amigo ${ }^{1}$, Juan Carlos Sanchez Zanotti ${ }^{1}$, Florentina García Calle ${ }^{1}$, Juan Carlos Nieto ${ }^{1}$, Belén Serrano Benavente ${ }^{1}$, Juan Ovalles ${ }^{1}$, Tamara Del Río Blasco ${ }^{1}$, Alfonso Ariza ${ }^{1}$, Carlos Gonzalez ${ }^{1}$, Indalecio Monteagudo Sáez ${ }^{1} .{ }^{1}$ Hospital General Universitario Gregorio Marañón, Madrid, Spain; ${ }^{2}$ Psicología Isabel Pinillos, Madrid, Spain

Background: In patients with rheumatic diseases, suicidal ideation (Si) and suicide attempt (Sa) have been observed more frequently than in the general population.

Objectives: 1. To determine the prevalence of $\mathrm{Si}$ and $\mathrm{Sa}$ in patients with biological therapies. 2. To evaluate possible factors associated with the Si.
Methods: Observational cross-sectional study in patients with intravenous BT from Day Hospital of a tertiary hospital in Madrid. Sociodemographic, disease features [weight, height, work disability (WD), diagnosis, treatment] and PRO (FiRST, FACIT-F, HAD, and GHQ-28) were collected. We defined the Si according to the answer at the $6^{\text {th }}$ and $7^{\text {th }}$ questions of section D of the GHQ-28. The Sa was registered according the patient's clinical history. The categorical variables were analyzed with the Chi square test. A logistic regression analysis was performed to evaluate the possible factors associated with suicidal behavior (SB). To evaluate the variance of discrete quantitative variables between groups the Krus kal-Wallis test was used, with a post-hoc analysis with U-Mann Whitney, to determinate the difference between pairs.

Results: We included 321 patients, 65\% women, with a mean age (range, SD) of 56 years $(89-15,14.1)$, and a mean disease duration (range, SD) of 16 years, DS $(53-1,9.7)$. The sociodemographic and clinical characteristics are described in Table 1 and 2. Of all patients, $4 \%$ had had 1 or more $\mathrm{Sa}$ and $11 \%$ had Si. $23 \%$ of patients had associated fibromyalgia (FiRST), 47\% fatigue (FACIT-F), 27.4\% anxiety (A-HAD), $16.2 \%$ depression (D-HAD) and a $48.6 \%$ a probable psychic disorde (GHQ-28). The final logistic regression model includes FACIT-F, IL, D $\mathrm{HAD}$, and first biological with Cox $\mathrm{R}^{2}$ and Snell $20.1 \%$ and Nagelkerke $35.5 \%$. The area under the curve was 0.849 with significance $p<0.0001$ [95\% Cl (0.786 - 0.912)]. Regarding the GHQ-28 score, a significant difference was observed among the diagnostic groups ( $p<0.001)$; in postHoc, a lower score was observed among patients with ankylosing spondylitis $p<0.001$. We also observed a significant difference among the treatment groups $(p<0.001)$ for the GHQ-28 score. In the post-hoc analysis, the Abatacept group had a significantly higher mean $p=0.042$ of GHQ-28 score, however, in the multivariate analysis no significant difference was observed $p=0.416$

Conclusion: There is a high prevalence of $\mathrm{Si}$ and $\mathrm{Sa}$ in patients with BT. Depression, fatigue, sleep disorders, fibromyalgia and work disability were associated with a higher prevalence of SB.

Table 1. Demographic characteristics No ideation/No attempt (273) Ideation (36) Attempt (12)

\begin{tabular}{|l|c|c|c|}
\hline \multicolumn{4}{|c|}{ Table1. Demographic characteristics } \\
\hline & No ideation/No attempt (273) & Idcation (36) & Attempt (12) \\
\hline Gender, \% females & $171(62,6)$ & $28(77,78)$ & $9(75)$ \\
\hline Age [Media(DS)] & $55,8(14,41)$ & $55,8(11,48)$ & $58,7(16,45)$ \\
\hline BMI (DS) & $25,6(4,62)$ & $25,8(4,97)$ & $27,0(4,67)$ \\
\hline Work disability (\%) & $55(20,14)$ & $14(38,88)$ & $6(50)$ \\
\hline Difficulty to sleep (yes) & $136(49,81)$ & $27(75)$ & $8(66,67)$ \\
\hline Disease duration Media (DS) & $15,7(9,89)$ & $17,3(8,81)$ & $13,9(9,15)$ \\
\hline
\end{tabular}

Table 2. Clinical characteristics

\begin{tabular}{lccc}
\hline & No ideation/No attempt (273) & Ideation (36) & Attempt (12) \\
\hline Diagnostic (\%) & & & \\
Rheumatoid arthritis & $125(45,78)$ & $20(55,55)$ & $5(41,66)$ \\
Ankylosing spondylitis & $94(34,43)$ & $6(16.6)$ & $3(25)$ \\
Psoriatic arthritis & $20(7,3)$ & $4(11,11)$ & $0(0)$ \\
Others & $34(12,4)$ & $6(16,6)$ & $4(33,33)$ \\
Treatment (\%) & & \\
Infliximab & $159(58,24)$ & $16(44,44)$ & $3(25)$ \\
Tocilizumab & $46(16,84)$ & $8(22,2)$ & $2(16,67)$ \\
Abatacept & $12(4,3)$ & $6(16,67)$ & $2(16,67)$ \\
Rituximab & $49(17,94)$ & $5(13,88)$ & $5(41,67)$ \\
Others & $7(2,5)$ & $1(2,7)$ & $0(0)$ \\
Previous biologic (yes) & $107(39,19)$ & $25(69,44)$ & $8(66,67)$ \\
FiRST >5 (\%) & $49(17,94)$ & $15(41,66)$ & $9(75)$ \\
FACIT-F < 34 (\%) & $109(39,92)$ & $31(86,11)$ & $11(91,67)$ \\
GHQ-28 >5 (\%) & $114(41,75)$ & $34(94,44)$ & $8(66,67)$ \\
CGHQ-28 >12 (\%) & $216(79,12)$ & $36(100)$ & $11(91,67)$ \\
A-HAD $>11(\%)$ & $61(22,34)$ & $21(58,33)$ & $6(50)$ \\
D-HAD >11 (\%) & $26(9,5)$ & $20(55,55)$ & $6(50)$ \\
\hline
\end{tabular}

Disclosure of Interests: Amparo Lopez Esteban : None declared, Roberto Daniel Gonzalez Benitez: None declared, Aurora Alonso Amigo: None declared, lustina Janta: None declared, Juan Carlos Sanchez Zanotti: None declared, Florentina García Calle: None declared, Juan Carlos Nieto: None declared, Belén Serrano Benavente: None declared, Juan Ovalles: None declared, Tamara Del Río Blasco: None declared, Alfonso Ariza: None declared, Carlos Gonzalez Consultant for: Celgene, Gilead Janssen, Merk, Novartis, Pfizer, Speakers bureau: Celgene, Roche, UCB, Indalecio Monteagudo Sáez: None declared DOI: 10.1136/annrheumdis-2019-eular.6887 